\title{
Body posture changes in women with migraine with or without temporomandibular disorders
}

\author{
Mariana C. Ferreira ${ }^{1}$, Débora Bevilaqua-Grossi ${ }^{2}$, Fabíola É. Dach ${ }^{3}$,
} José G. Speciali ${ }^{3,4}$, Maria C. Gonçalves ${ }^{5}$, Thais C. Chaves ${ }^{4}$

\begin{abstract}
Background: Migraine and temporomandibular disorders (TMDs) are reported to be associated. However, there are no reports on the association among migraines, TMDs and changes in body posture. Objectives: To assess changes in body posture in women suffering migraines with or without TMD compared with a control group. Method: Sixty-six women with a mean age of 18 to 45 years participated in this study. The groups were composed of 22 volunteers with migraine and TMD (MTMD), 22 volunteers with migraines without TMD (MG) and 22 women in the control group (CG). Static posture was assessed by photogrammetry, and 19 angles were measured. Results: Postural asymmetry was observed in the face for 4 angles measured on the frontal plane in the MG group and for 4 angles of the trunk in the MG and MTMD groups with respect to CG. However, for comparisons between MTMD and CG, clinical relevance was identified for two angles of the sagittal plane (Cervical and Lumbar Lordosis, Effect Size - ES - moderate: 0.53 and 0.60). For comparisons between the MG and CG, the clinical relevance/potential was verified for three angles with moderate ES (ES>0.42). The clinical relevance when comparing MTMD and CG was identified for four angles of facial symmetry head inclination (ES>0.54) and for two angles between MG and CG (ES>0.48). Conclusion: The results demonstrated the presence of postural changes compared with a control group in women with migraines with or without TMD, and there were similar clinically relevant postural changes among the patients with migraines with and without TMD.
\end{abstract}

Keywords: posture; migraine disorders; temporomandibular joint disorders; physical therapy.

\section{HOW TO CITE THIS ARTICLE}

Ferreira MC, Bevilaqua-Grossi D, Dach FÉ, Speciali JG, Gonçalves MC, Chaves TC. Body posture changes in women with migraine with or without temporomandibular disorders. Braz J Phys Ther. 2014 Jan-Feb; 18(1):19-29. http://dx.doi.org/10.1590/ S1413-35552012005000137

\section{Introduction}

Several methods for assessing static posture have been reported in the literature, including qualitative methods, such as visual observation, and quantitative methods, where images are analyzed using specific software such as photogrammetry ${ }^{1,2}$. Prior studies have demonstrated good levels of intra- and interrater reliability for the technique of assessing posture by photogrammetry ${ }^{3-5}$.

Body posture changes can be associated with many disorders, including painful syndromes ${ }^{6}$, such as migraines ${ }^{7}$, and musculoskeletal disorders ${ }^{8}$, such as temporomandibular disorders (TMD) $)^{9-13}$. However, assessments of craniocervical posture have only previously been tested in patients with $\mathrm{TMD}^{13}$ and in individuals with migraines?

One possible explanation for the association between changes in craniocervical posture in patients with migraines and TMD is the mechanism of convergence of trigeminal and cervical afferents onto the same neurons in the brainstem ${ }^{14}$. This convergence of afferent nerves can lead to the development of cervical pain symptoms in patients with TMD and migraines, resulting in a limited range of motion ${ }^{15}$ and changes in head and cervical posture. Changes in body posture may appear as a compensatory mechanism, especially in adjacent body segments.

Migraine is a chronic headache that manifests episodically and is characterized by recurring attacks involving headaches that are typically unilateral, pulsating and of moderate to severe intensity ${ }^{16}$. Migraines are more common in women ${ }^{17,18}$.

TMD is a disorder of the temporomandibular joints (TMJs) and/or masticatory muscles and associated structures ${ }^{19}$ and can cause the following signs and symptoms: pain in the preauricular region, pain in the TMJ and associated structures, restricted mandibular

\footnotetext{
${ }^{1}$ Physical Therapy Program, School of Medicine of Ribeirão Preto (FMRP), Universidade de São Paulo (USP), Ribeirão Preto, SP, Brazil ${ }^{2}$ Department of Biomechanics, Medicine and Rehabilitation of Locomotor, FMRP, USP, Ribeirão Preto, SP, Brazil

${ }^{3}$ Craniofacial Pain Outpatient Clinic, Hospital das Clínicas de Ribeirão Preto (HCRP), USP, Ribeirão Preto, SP, Brazil

${ }^{4}$ Department of Neurosciences and Behavioral Sciences, FMRP, USP, Ribeirão Preto, SP, Brazil

${ }^{5}$ Graduate Program in Orthopedics, Traumatology and Rehabilitation of the Locomotor System, FMRP, USP, Ribeirão Preto, SP, Brazil Received: 12/07/2012 Revised: 06/11/2013 Accepted: 09/11/2013
} 
movement, and TMJ noise ${ }^{20-22}$. In Brazil, $37.5 \%$ of the population may present with one of these symptoms ${ }^{23}$.

In addition to the association among TMD, migraines, and changes in body posture, there are published reports of a possible association between migraine and $\mathrm{TMD}^{24-28}$. One of the described mechanisms is the ability of TMD to aggravate a pre-existing headache or to acting as a risk factor for migraine ${ }^{26}$.

Despite indications that both conditions are associated with changes in body posture, we could find no published studies that examined the effect of the overlap of these disorders on the development of craniocervical and global posture or studies on the presence of posture changes in individuals with those disorders separately. Therefore, the hypotheses tested in the present study are that there are body posture differences in women with migraines compared with a group of women without migraine and that the presence of both migraines and TMD amplifies such differences.

The present study aimed to detect changes in static body posture in patients with migraine in the presence or absence of TMD when compared to a control group (CG).

\section{Method}

This was a cross-sectional case-control study with three groups of 22 female participants aged 18 to 50 years. The groups consisted of patients with migraines and TMD (MTMD), patients with migraines without TMD (MG), and volunteers in the CG. Taking the forward head posture (FHP) as the main variable, a power effect of 0.99 and an effect size of $0.74(=0.05)$ were obtained from a sample size of 66 subjects (22 per group). The GPower ${ }^{\circledR}$ 3.0.10 software (Franz Faut, Universität Kiel Germany, 2008) was used for analyses. No significant differences were found between groups with respect to the anthropometric data of the samples (Table 1).

This study was approved by the Research Ethics Committee of the Teaching Hospital at the School of Medicine of Ribeirão Preto, Universidade de São Paulo - HCFMRP-USP, Ribeirão Preto, state of São Paulo-SP, Brazil, under protocol number 4732/2011. All study volunteers signed an informed consent form to participate in the study.

\section{Inclusion and exclusion criteria}

Patients with migraines were selected consecutively from the Craniofacial Pain Outpatient Clinic of HCFMRP-USP.
Migraine was diagnosed by neurologists according to the criteria set by the International Classification of Headache Disorders ${ }^{16}$. Patients with a stable clinical condition for at least three months with a frequency of 2-12 days with migraine pain per month were included. Patients were assessed for the presence of TMD according to axis I of the Research Diagnostic Criteria for Temporomandibular Disorders (RDC/ TMD) $)^{29}$.

Volunteers with no prior diagnoses or signs or symptoms of migraine or TMD in the last 12 months were accepted to the CG. These volunteers were selected from employees and students at the University of São Paulo Campus. The CG volunteers were selected based on their similar weight, height and age relative to the MTMD and MG groups.

The exclusion criteria were as follows: a diagnosis of any other type of headache (except infrequent episodic tension-type headaches of fewer than three attacks per year), any other chronic pain, diagnosed postural changes (scoliosis/limb length discrepancies/ hyperkyphosis/amputations/hemiplegias), acute pain at the time of assessment, previous treatment by postural intervention, and a history of traumas involving clinical repercussions (cranial traumas/ bone fractures/cervical whiplash).

\section{Assessment of temporomandibular disorder (TMD)}

RDC/TMD axis $\mathrm{I}^{29}$ was applied by a single trained examiner as recommended by the international consortium: http://www.rdc-tmdinternational.org/. The tool consists of a clinical assessment protocol widely used in research ${ }^{29}$. The RDC/TMD consists of measuring the range of mandibular motion, an assessment of pain on palpation, and observations of clicking and crepitus during motion ${ }^{30}$.

\section{Assessment of body posture}

The patients were assessed using photographic records in the orthostatic position from the anterior, posterior, and lateral views. The volunteers were instructed to look at a fixed point on the wall at a distance of $1 \mathrm{~m}$. After a brief walk around the laboratory, the volunteers were asked to position themselves at the site to be photographed.

A Canon Rebel EOS-300 digital camera was placed on a tripod, and the tripod center was positioned at a fixed distance of $4 \mathrm{~m}$ from the volunteer ${ }^{32}$. For whole body photographs, the center of the camera lens was fixed at a height corresponding to the individual's midpoint; a $35 \mathrm{~mm}$ objective was used $^{31,32}$. For facial photographs, the center of 
Table 1. Mean values (standard deviations, SD) of the anthropometric data and descriptions of the clinical data of the studied samples.

\begin{tabular}{|c|c|c|c|c|}
\hline Variables/Groups & $\begin{array}{c}\text { Migraine + TMD }(\mathbf{n}=22) \\
\text { Mean }(\text { SD) }\end{array}$ & $\begin{array}{c}\text { Migraine }(\mathrm{n}=22) \\
\text { Mean }(\mathrm{SD})\end{array}$ & $\begin{array}{c}\text { Control }(\mathbf{n}=22) \\
\text { Mean }(\mathrm{SD})\end{array}$ & P-level* \\
\hline Age (years) & $30.27(11.46)$ & $31.72(9.82)$ & $24.41(6.95)$ & NS \\
\hline Height (m) & $1.65(0.06)$ & $1.65(0.05)$ & $1.65(0.08)$ & NS \\
\hline \multirow[t]{2}{*}{ Weight (kg) } & $62.31(8.15)$ & $66.81(18.69)$ & $63.64(10.75)$ & NS \\
\hline & & Raw values & & \\
\hline Time of onset of disease (years) & 11.5 & 14.3 & NA & \\
\hline Days of migraine attacks & 7.8 & 8.3 & NA & \\
\hline \multicolumn{5}{|l|}{ Side of headache complaint } \\
\hline $\mathrm{R}$ & 8 & 6 & NA & \\
\hline $\mathrm{L}$ & 3 & 3 & NA & \\
\hline Bilateral/Unilateral & 11 & 13 & NA & \\
\hline \multicolumn{5}{|l|}{ TMD mixed } \\
\hline Group Ia/IIa** & 14 & 0 & 0 & \\
\hline Group Ib/IIb** & 1 & 0 & 0 & \\
\hline Group Ia/IIc** & 4 & 0 & 0 & \\
\hline \multicolumn{5}{|l|}{ Myogenous TMD } \\
\hline Group Ia** & 3 & 0 & 0 & \\
\hline
\end{tabular}

$\mathrm{NA}=$ not applicable; NS = not significant; *ANOVA $(\mathrm{p}<0.05)$; * Description of RDC/TMD diagnostics subgroups Group I - Myogenous Diagnosis: Ia - Ib and Myofascial Pain - Myofascial pain with limited opening. Group II - Disc Displacement: IIa - disc displacement with reduction; IIb - disc displacement without reduction and with limited opening; and IIIc- disc displacement without reduction and without a limited opening. Group III - Arthralgia, Arthritis and Osteoarthritis: IIIa - Arthralgia; IIIb - IIIc and TMJ Osteoarthritis - Osteoarthritis of the TMJ.

the camera lens was positioned on the center of the glabella; a 105 m objective was used ${ }^{33}$.

The method for obtaining and recording images has been previously described ${ }^{4}$. Anatomical reference points were defined based on bone palpation by a single examiner who was previously trained on the placement of markers ${ }^{4}$, which demonstrated good levels of experimental reproducibility (Figure 1).

\section{Photographic analysis}

The images were analyzed using the application Corporis Pro 3.1 (Data Hominis Tecnologia ${ }^{\circledR}$, Uberlândia, Minas Gerais, Brazil) using measurements of the angles formed by the lines traced from the anatomical points.

All images were analyzed by a single examiner blinded to the study groups. Thirteen angles of asymmetry in the frontal plane were obtained from the anterior and posterior views, and six angles were obtained in the sagittal plane.

Nineteen angles previously described in the literature were analyzed ${ }^{4,5}$. The way in which these angles were traced during the analyses and the method of interpretation are described in Table 2.

\section{Reliability}

The analysis of intrarater reliability of the tracings was performed by randomly selecting 15 records of study participants. The tracings were initially made and then repeated after a period of seven days. Analyses were always performed by the same previously trained examiner (20 hours of training).

\section{Data analysis}

Analysis of variance (ANOVA, $\mathrm{p}<0.05$ ) was used to compare the mean values of angles measured across the three groups of the present study and the post-hoc Bonferroni test. The Intraclass Correlation Coefficient (ICC) was used to test the reliability of the measurements. The following ranges were considered when rating the reliability: ICC $<0.4$, poor reliability; $0.4<\mathrm{ICC}<0.75$, moderate reliability; and ICC $>0.75$, excellent reliability ${ }^{34}$. The associations between posture tracings (dependent variables) and the following independent variables were analyzed by multiple linear regression: weight, age, and height. The significance of the final model was tested by the ANOVA F-test, and the goodness of fit was assessed by the adjusted coefficient of determination (adjusted 
$\mathrm{R}^{2}$ ). The SPSS, Inc. software version 17 (Chicago IL, USA) was used to perform the statistical analyses.

The following formula was used to analyze the standard error of the measurement: SEM=SD $\sqrt{ } \operatorname{ICCI}(1-\mathrm{ICC})^{35}$. The effect size was analyzed using the following formula: $\mathrm{ES}=(\mathrm{MG} 1-\mathrm{MG} 2) / \mathrm{SD}$ polled, where $\mathrm{ES}=$ effect size, $\mathrm{M}=$ mean, $\mathrm{SD}$ pooled = pooled standard deviation $\left(\mathrm{SD}\right.$ pooled $=\sqrt{ } \mathrm{SD}_{1}{ }^{2}\left(\mathrm{~N}_{1}{ }^{-}\right.$ 1) $+\mathrm{SD}_{2}^{2}\left(\mathrm{~N}_{2}-2\right) / \mathrm{N}_{1}+\mathrm{N}_{2}-2$, where $\mathrm{N}=$ sample size,

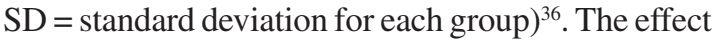
sizes were classified according to Cohen ${ }^{37}$ : small effect size (SES), 0.20 (0-0.39); medium effect size (MES), 0.50 (0.4-0.79); and large effect size (LES), $>0.80$.

The Minimal Important Difference (MID) was calculated by multiplying the ES of 0.2 and 0.5 (small and medium ES, respectively, according to Cohen ${ }^{37}$ ) by the SD pooled across two groups using the following formulas ${ }^{38}: \mathrm{MID}_{1}=0.2 \times \mathrm{SD}$ pooled and $\mathrm{MID}_{2}=0.5 \times$ SD pooled.

In the present study, clinically relevant differences were defined as follows: a) a mean difference between the groups greater than the $\mathrm{MID}^{38}$; b) an effect size greater than 0.40; and c) a mean difference between groups greater than the SEM.

\section{Results}

The MG and MTMD did not differ in terms of the years since disease onset, laterality of pain, or the number of attacks per month (Table 1). There were no significant differences between the groups with respect to age, weight, or height. Multiple linear regression revealed only a single association between the acromioclavicular joint angle (AC) and the independent variables weight and age, with $\mathrm{R}^{2}<0.30$ and $\mathrm{p}<0.05$.

The TMD diagnostics obtained according to the RDC/TMD are described in Table 1.

Reliability was only classified as moderate for two angles (EO and CLA). Reliability was considered excellent for the remaining angles (17 angles) (Table 3$)^{35}$. Despite having moderate (EO, CLA) or excellent (SC, ATP, CLA) ICC values, some angles exhibited a wide confidence interval classified as excellent to low (Table 3).

From the frontal view, the MG exhibited greater mean values than the MTMD and the CG for the EO and IO values (Table 3 ). The AC was also significantly smaller in the MTMD. The sternoclavicular joint angle (SC) and the angle of the ear tragus (AET) were
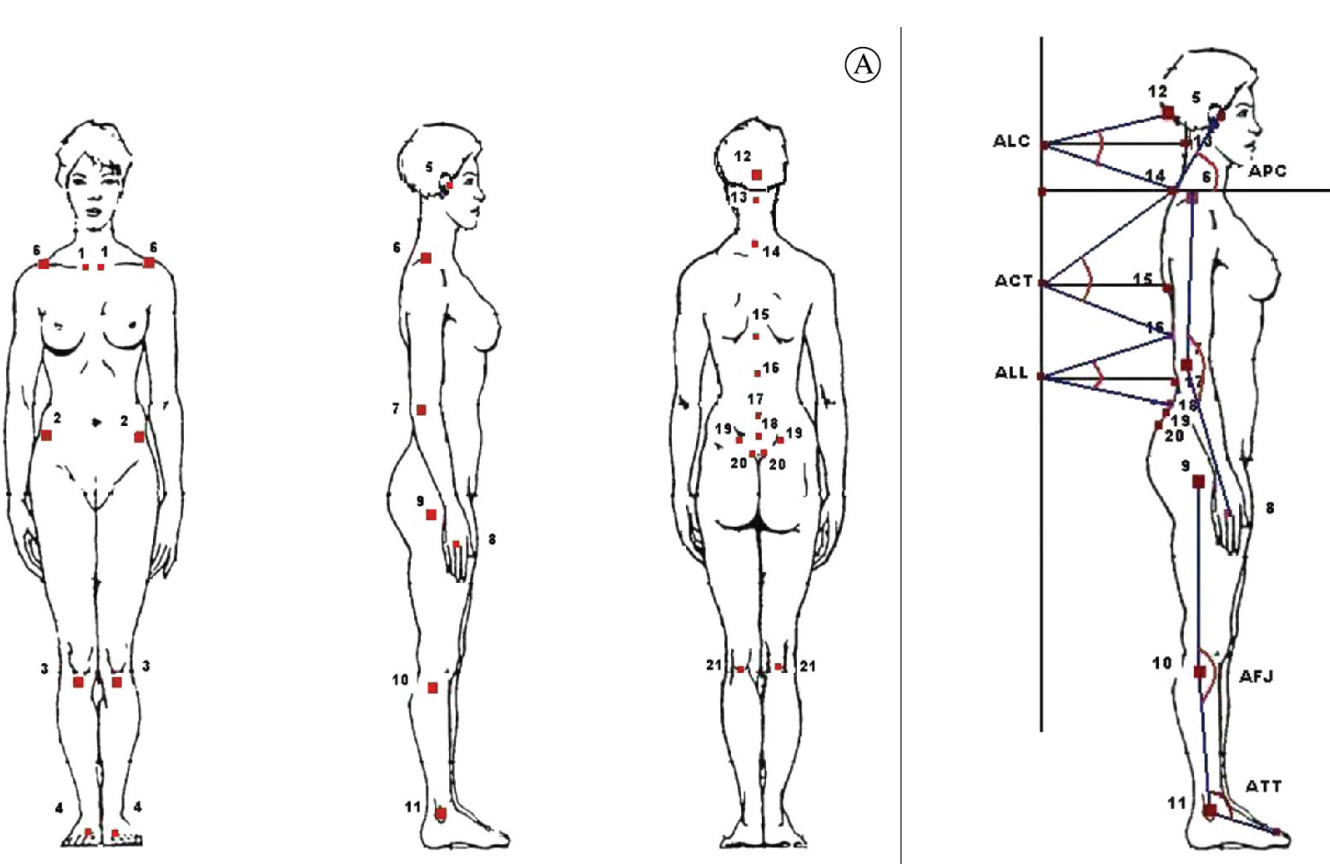

Figure 1. A) Schematic picture demonstrating the 21 anatomical points considered for postural analysis. B) Illustrative scheme from a sagittal view. forward head posture(FHP), cervical lordosis angle (CLA), thoracic kyphosis angle (TKA), and Lumbar lordosis angle (LLA). Anatomical points considered: 1 - sternoclavicular joints; 2 - anterosuperior iliac spines; 3 - anterior tibial tuberosity; 4 - second toe, metatarsophalangeal joint; 5 - tragus of the ear; 6 - acromion of scapula; 7 - lateral epicondyle of elbow; 8 - metacarpophalangeal joint of the 3rd finger; 9 - greater trochanter; 10 - head of fibula; 11 - malleolus lateral ankle; 12 - occipital protuberance; 13 - third cervical vertebra; 14 - 7th cervical vertebra; 15 - seventh thoracic vertebrae; 16 - twelfth thoracic vertebra; 17- third lumbar vertebra; 18- fifth lumbar vertebra; 19 - posterior superior iliac spines; 20 - posterior inferior iliac spines; and 21 - midpoint of poplietal line. 
Table 2. Description of the method of measurement of the 19 angles considered and their benchmarks.

Angle Acronym Obtaining/Reference Values $(x=$ angle $)$

\section{Angles Frontal Plane - Face and Shoulder Girdle / Anterior View / Posterior View}

Internal Orbicular Angle

External Orbicular Angle

Comissura Labiorum Angle

Acromion-Clavicular joint Angle

Sternoclavicular Joint Angle

Angle of Ear Tragus

Anterior Superior Iliac Spines Angle

Angle between the Tibial Protuberance

Inferior Angle of the Scapula

Central Region of Olecranon Angle

Posterior Superior Iliac Spines Angle

Posterior Inferior Iliac spines Angle

Popliteal Line Angle

\section{Sagittal Plane Angles}

Forward Head Posture (FHP)

Cervical lordosis (CL)

Thoracic kyphosis (TKA)

Lumbar lordosis (LLA)

Knee flexor $(\mathrm{KF})$

Tibiotarsal angle (TTA)

IO

CLA

$\mathrm{AC}$

$\mathrm{SC}$

AET

AS

ATP

IS

OC

PS

PI

PL

\section{Method and Reference Values}

Measured from the tragus of the ear to the spinous process of $\mathrm{C} 7$, extending forward on the horizontal line. *

Angle formed by the straight lines between the occipital protuberance and the spinous process of $\mathrm{C} 7$ that intersects the horizontal line between $\mathrm{C} 4$ and the true vertical line - plumb line*

Angle formed by the straight lines between the spinous process of $\mathrm{C} 7$ and $\mathrm{T} 12$ that intersect the horizontal line between $\mathrm{T} 7$ and the true vertical line*

Angle formed by the straight lines between the spinous processes of T12 and L5 that intersect the horizontal line between L3 and the true vertical line*

Angle formed by the straight line between the points on the greater trochanter of the femur and the head of the fibula and the straight line that passes through the head of the fibula and extends vertically downwards $* *$

Angle formed by the straight line between the head of the fibula and the lateral malleolus of the foot and the straight line that joins the lateral malleolus and the head of the fifth metatarsus*

*No reference values/**EJ>180: suggested knee hyperextension and $\mathrm{EJ}<180$ : suggests knee flexion.

significantly greater in the MG than in the MTMD or the CG (Table 3).

However, the differences between the MG and CG were clinically relevant (potential or not) only for EO (ES=0.49; MES), AET (ES=0.44; MES), and AC (ES=1.36; LES); the effect sizes obtained for these measurements were at least moderate, and the mean differences between the groups were greater than the MID (MID 0.2 and 0.5) and the SEM (Table 4). All significant differences found between the MTMD and MG with respect to the angles of facial symmetry/ head inclination were clinically relevant, with the exception of the external orbicular angle (EO). The IO, AC, and SC had an ES $>0.80$ (LES), and the AET and CLA had ESs between 0.40 and 0.80 (MES), with the mean differences between the groups greater than the MID (MID 0.2 and 0.5) and the SEM (Table 4).

In the sagittal plane, smaller angles were observed in the MG and MTMD compared to the CG for forward head posture (FHP), cervical lordosis (CL) and thoracic kyphosis (TKA). The mean lumbar lordosis angle (LLA) was significantly greater in 
the MG and MTMD than in the CG. The MG and MTMD differed significantly with respect to TKA and LLA (smaller TKA and greater LLA in the MTMD) (Table 3). Only the significant differences for CLA (ES=0.53 and 0.42, both MES) and LLA ( $\mathrm{ES}=0.60$, LES) were clinically relevant; the ESs were moderate, and the mean differences between the groups were greater than MID 0.2, MID 0.5, and the SEM (Table 4).

In the frontal plane posterior view, the inferior angle of the scapula (IS), the posterior inferior iliac spines (PI), and the central angle of the popliteal line (PL) were significantly smaller in the CG compared with the MG and MTMD (Table 3). However, none of these angles exhibited clinically relevant differences (Table 4).

\section{Discussion}

The main objectives of the present study were to test for differences in postural patterns between women with migraine with or without TMD compared with a CG and to test whether the presence of migraine and TMD can exacerbate such differences. The hypothesis tested was partly proved because body postural changes were detected in women with migraine with and without TMD relative to the CG; however, the analysis of clinical relevance revealed that the posture changes were similar in the MG and MTMD. Thus, this analysis demonstrated that some of the significant differences observed should be interpreted cautiously.

Regarding the instrument for posture analysis used in the present study, there was excellent intrarater

Table 3. Intraclass Correlation Coefficients (ICC), mean values and confidence intervals (95\%) of the 19 measured angles (degrees) in the patients with migraines (MG), patients with migraines and temporomandibular disorders (MTMD), and the control group (CG).

\begin{tabular}{|c|c|c|c|c|}
\hline Angles & $\begin{array}{l}\text { Mean ICC } \\
(\text { CI 95\%) }\end{array}$ & $\begin{array}{l}\text { MTMD }(n=22) \\
\text { Mean }(\text { CI } 95 \%)\end{array}$ & $\begin{array}{l}\text { MG }(n=22) M \\
\text { ean }(C I 95 \%)\end{array}$ & $\begin{array}{c}\text { CG }(n=22) \\
\text { Mean }(\text { CI } 95 \%)\end{array}$ \\
\hline $\mathrm{EO}$ & $0.71(0.90-0.15)$ & $181.71(182.12-181.30)$ & $182.22(182.59-181.84)^{*}$ & $181.51(181.86-181.16)$ \\
\hline $\mathrm{IO}$ & $0.76(0.80-0.40)$ & $181.24(181.41-181.07)$ & $182.21(182.61-181.96)^{*}$ & 181.53 (181.01-181.04) \\
\hline $\mathrm{AC}$ & $0.88(0.96-0.66)$ & $181.07(181.24-180.91)^{*}$ & $182.29(182.62-181.96)$ & $182.48(182.89-182.08)$ \\
\hline $\mathrm{SC}$ & $0.78(0.92-0.35)$ & 181.64 (181.44-181.03) & $182.05(182.39-181.71)^{*}$ & $181.64(182.04-181.23)$ \\
\hline AET & $0.82(0.84-0.49)$ & $181.11(181.28-180.94)$ & $181.75(182.11-181.39)^{*}$ & $181.26(181.52-181)$ \\
\hline CLA & $0.66(0.88-0.03)$ & $181.16(181.36-180.96)$ & $181.55(181.86-181.25)$ & $181.21(181.51-180.91)$ \\
\hline FHP & $0.96(0.98-0.90)$ & $67.83(68.89-66.78)$ & 69.88 (71.19-68.58) & $73.03(74.68-71.39)^{*}$ \\
\hline CL & $0.79(0.93-0.39)$ & $14.63(15.04-14.23)$ & $14.99(15.39-14.59)$ & $16.38(17.04-15.72)^{*}$ \\
\hline TKA & $0.97(0.99-0.93)$ & $40.13(41.02-39.24)^{*}$ & $42.93(44.60-41.27)^{*}$ & $47.27(49.03-45.51)$ \\
\hline LLA & $0.93(0.97-0.81)$ & $27.19(28.18-26.20)^{*}$ & $25.48(26.47-24.48) *$ & $22.68(23.32-22.04)$ \\
\hline $\mathrm{KF}$ & $0.99(1.00-0.99)$ & $181.53(183.44-179.62)$ & $182.26(183.80-180.72)$ & $182.02(184.18-179.86)$ \\
\hline TTA & $0.98(0.99-0.96)$ & $100.31(101.41-99.20)$ & $101.00(102.18-99.82)$ & $99.47(101.34-97.60)$ \\
\hline IS & $0.98(0.99-0.95)$ & $181.81(182.49-181.13)$ & $181.29(181.48-180.09)$ & $179.12(180.52-177.71)^{*}$ \\
\hline $\mathrm{OC}$ & $0.88(0.96-0.66)$ & $180.86(181.49-180.22)$ & $181.03(181.77-180.29)$ & $180.02(180.66-179.38)$ \\
\hline PS & $0.98(0.99-0.94)$ & $181.84(182.68-180.59)$ & 181.85 (183.04-180.66) & $180.13(181.34-178.92)$ \\
\hline PI & $0.96(0.98-0.89)$ & $183.27(184.48-182.05)$ & $183.86(184.97-182.75)$ & $180.58(183.04-180.13)^{*}$ \\
\hline PL & $0.95(0.98-0.87)$ & $182.10(183.20-181.01)$ & $182.65(184.97-182.75)$ & $179.89(180.93-178.85)^{*}$ \\
\hline AS & $0.86(0.95-0.60)$ & $184.40(183.01-181.36)$ & $182.23(184.21-182.26)$ & $182.95(184.04-181.85)$ \\
\hline ATP & $0.76(0.92-0.31)$ & $181.76(181.80-180-87)$ & 181.95 (181.26-181.62) & $181.48(181.83-181.13)$ \\
\hline
\end{tabular}

*Difference compared to the other groups - ANOVA, $\mathrm{p}<0.05$ and post-hoc Bonferoni. NS: Not Significant. IO - internal orbicular angle EO - external orbicular angle; CLA - comissura labiorum angle; AC - acromion-clavicular joint angle; SC - sternoclavicular joint angle; AET - angle of ear tragus; AS - anterior superior iliac spines angle; ATP - angle between tibial protuberance; IS - inferior angle of scapula; OC - central region of olecranon angle; PS - posterior superior iliac spines angle; PI - posterior inferior iliac spines angle; PL - popliteal line angle; FHP - forward head posture; CL - cervical Lordosis; TKA - thoracic kyphosis; LLA - lumbar lordosis; KF - knee flexor; TTA - tibiotarsal angle. 
reliability for most of the postural recordings. The ICC exhibited a wide confidence interval for five angles (EO, SC, CLA, ATP and CL), ranging from excellent to low ICCs. However, of these angles, only CL and SC were statistically significant and clinically relevant, and the lower bounds of the confidence intervals were very near the value considered moderate ( 0.39 and 0.35 , respectively). These findings suggest low variability for the measurements used and low examiner error for the preparation of the angle tracings (SEM between 0.25 and 1.04). Prior studies have used the same method for assessing posture and reported moderate to excellent intra- and inter-examiner reliability ${ }^{4,5}$.

The results of the present study revealed significant differences in the postural angles between groups, and the main results were as follows: a) there were clinically relevant differences between the MG and MTMD relative to the CG for only two angles in the sagittal plane and one angle of asymmetry of the shoulder girdle, with potentially clinical differences in two angles of facial asymmetry; b) there was no intensification of posture changes in women with migraine with TMD compared with those suffering only migraines, as it was not possible to assign clinical relevance to the differences between the MG and MTMD; and c) asymmetries were more often found in the MG than in MTMD.

Migraine patients with or without TMD exhibited smaller angles of forward head posture, cervical lordosis, and thoracic kyphosis and a greater angle of lumbar lordosis compared with the CG. However, the only clinically relevant findings were the cervical lordosis angle in the MG and MTMD compared with the CG and the lumbar lordosis angle in the MTMD. Thus, the remaining differences can be considered statistically significant but clinically irrelevant.

The postural pattern of forward head posture has been observed in patients with headache. Watson and Trott $^{39}$ and Fernández-de-las-Peñas et al. ${ }^{40}$ reported a smaller craniovertebral angle (FHP) in patients with cervicogenic and tension-type headaches, respectively. In another study, Fernández-de-lasPeñas et al. ${ }^{7}$ also reported a smaller craniovertebral angle in migraine patients compared with a CG (suggesting greater forward head posture in the migraine group). Shifting the head forward may represent an antalgic posture used to reduce pain. Although a significant reduction in the craniovertebral angle was observed in migraine patients with or without TMD in the present study, this finding was not clinically relevant. Our results demonstrate that the MID for this measurement was at least $10.5^{\circ}$ (considering a moderate effect size of 0.5 ), but the observed mean differences between the groups were $5.20^{\circ}$ and $3.15^{\circ}$ for the MG and MTMD, respectively, relative to the $\mathrm{CG}$ (Table 4).

Published reports disagree on the presence of TMD and forward head posture. Visscher et al. ${ }^{41}$ and Iunes et al. ${ }^{42}$ did not observe differences in forward head posture between patients with TMD and healthy controls. In contrast, Lee et al. ${ }^{43}$ reported greater forward head posture in patients with TMD compared with a CG. None of the aforementioned studies analyzed clinical relevance. Armijo-Olivo et al. ${ }^{44}$ analyzed clinical relevance to investigate craniocervical posture parameters in patients with TMD compared with a CG. The authors identified a statistically significant but clinically irrelevant difference in only one of the posture parameters analyzed (eye-tragus-horizontal angle); the mean difference between the TMD and control groups $\left(2.6^{\circ}\right)$ was less than the MID $\left(2.7^{\circ}\right)$ for an effect size of 0.5 .

It is important to highlight the clinical relevance of two angles analyzed in the present study, the cervical lordosis and lumbar lordosis angles. The increase in the cervical lordosis angle was clinically relevant for migraine patients with and without TMD. The decrease in lumbar lordosis (greater lumbar lordosis angle) was clinically relevant for MTMD. Based on these findings, it is possible to suggest that body posture changes in migraine patients without TMD are restricted specifically to the cranial segment, whereas compensatory changes at other levels of the spine can occur in migraine patients with TMD. These data call attention to the importance of assessing body posture in migraine patients.

The angles of facial symmetry/head inclination were greater in the MG, suggesting that migraine without TMD is more related to postural changes in the frontal plane of the face. Of the six angles of facial symmetry/head inclination and shoulder girdle analyzed in the present study, four angles (EO, SC, AET, CLA) exhibited significant and clinically relevant differences $(\mathrm{ES}>0.5)$ between patients in the MG and those in the MTMD, and two angles (EO and AET) were potentially clinically relevant based on the mean difference between the MG and CG.

It is possible that such changes are related to facial asymmetry or head and cervical inclination in 


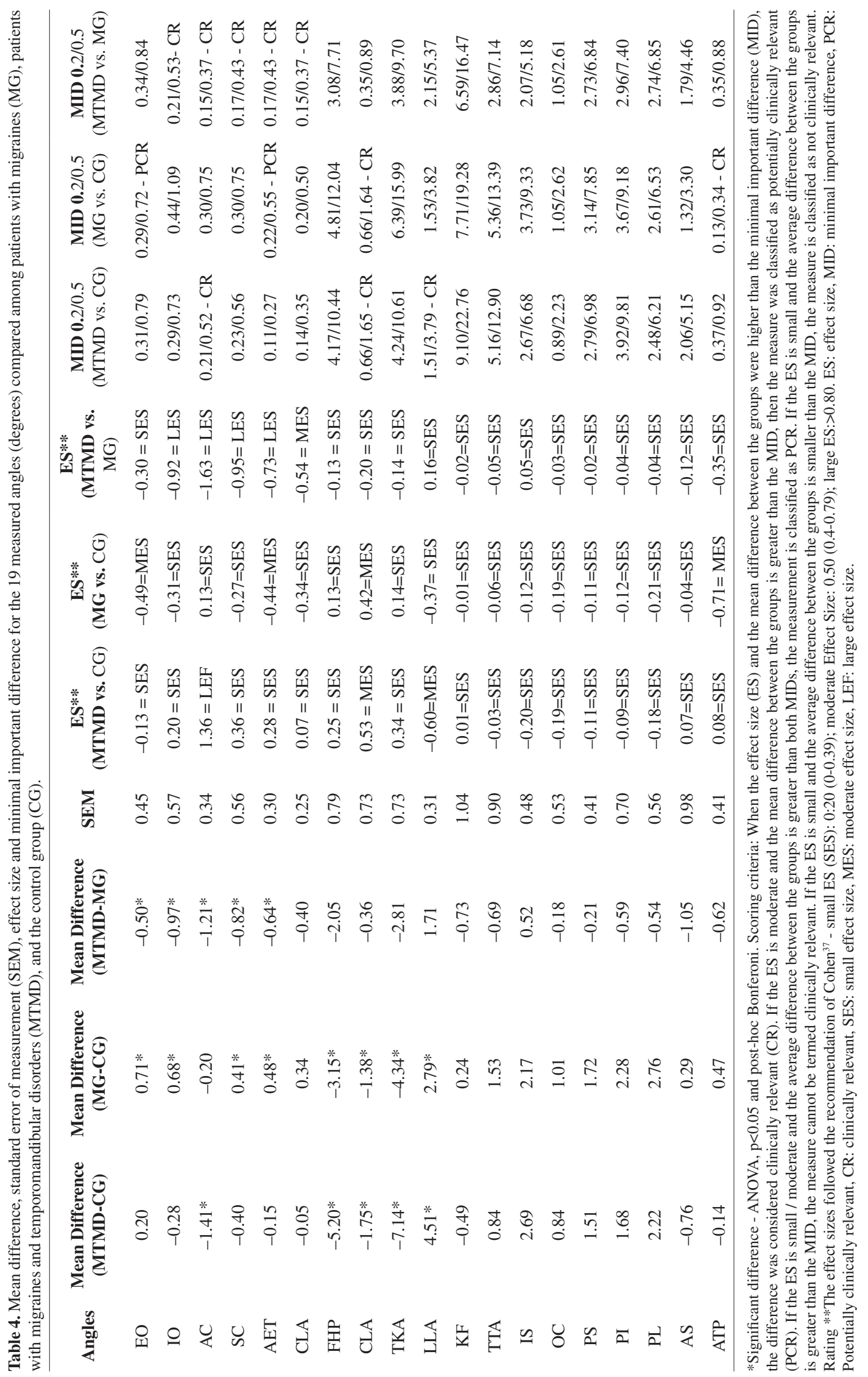


the frontal plane because there was a tendency for tilt to one side (value greater than $180^{\circ}$ - tilt to the right). These findings are possibly explained by the more frequent occurrence of headache on one side. Prior studies correlating the side most commonly afflicted with migraine to possible musculoskeletal changes reported a greater presence of active trigger points ipsilateral to the pain ${ }^{7}$, which could lead to the development of compensatory antalgic posture on the same side.

The shoulder girdle symmetry angle (AC) was significantly smaller in the MG and MTMD than in the CG. It should be noted that the greater weight of migraine patients and lower age of the controls could have affected these results because multiple regression analysis revealed a weak association between the variables. Therefore, the observed differences cannot be attributed exclusively to the presence of migraine and/or TMD.

These findings are novel, and there are no prior published reports involving the study of postural changes in migraine patients and the association between migraine and TMD. One limitation of the present study was the lack of a group with TMD without migraine. Longitudinal studies are required to test the causal relationships between migraine/ TMD and posture and to confirm the present findings. Knowledge of these factors will be important for guiding decision-making regarding physiotherapeutic interventions for these patients and may help to select a more global therapeutic approach.

\section{Conclusion}

The results of the present study demonstrated body posture changes in women with migraine with or without TMD compared with a CG. Such posture changes were similar between the MG and MTMD. Clinically relevant differences were observed between the MG and MTMD compared with the control group for two angles in the sagittal plane in the spinal region. Potentially clinically relevant differences were observed for the angles of facial asymmetry/head inclination for the MG relative to MTMD and CG. These findings call attention to the importance of assessing craniocervical posture in migraine patients and more comprehensive body posture assessment in migraine patients with TMD.

\section{Acknowledgements}

We would like to thank the São Paulo Research Foundation (FAPESP) for financial support (Process 2009/17580-4 and 2010/15034-0).

\section{References}

1. Ferrario VF, Sforza C, Tartaglia G, Barbini E, Michielon G. New television technique for natural head and body posture analysis. Cranio. 1995;13(4):24-55. PMid:9088166.

2. Zonnenberg AJJ, Maanen V, Elvers JWH, Oostendorp $\mathrm{RAB}$. Intra/interrater reliability of measurements on body posture photographs. Cranio. 1996;14(4):326-31. PMid:9110628.

3. Fortin C, Ehrmann Feldman D, Cheriet F, Labelle H. Clinical methods for quantifying body segment posture: a literature review. Disabil Rehabil. 2011;33(5):367-83. PMid:20568973. http://dx.doi.org/10.3109/09638288.2 010.492066

4. Belli JFC, Chaves TC, Oliveira AS, Bevilaqua-Grossi D. Analysis of body posture in children with mild to moderate asthma. Eur J Pediatr. 2009;168(10):120716. PMid:19132386. http://dx.doi.org/10.1007/ s00431-008-0911-y

5. Iunes DH, Castro FA, Salgado HS, Moura IC, Oliveira AS, Bevilaqua-Grossi D. Confiabilidade inter e intraexaminadores e repetibilidade da avaliação postural pela fotogrametria. Rev Bras Fisioter. 2005;9(3):327-34.

6. Ferreira EAG, Duarte M, Maldonado EP, Burke TN, Marques AP. Postural assessment software (PAS/SAPO): validation and reliability. Clinics. 2010;65(7):675-81. PMid:20668624 PMCid:PMC2910855. http://dx.doi. org/10.1590/S1807-59322010000700005

7. Fernández-de-Las-Peñas C, Cuadrado ML, Pareja JA. Myofascial trigger points, neck mobility and forward head posture in unilateral migraine. Cephalalgia. 2006;26(9):1061-70. PMid:16919056. http://dx.doi. org/10.1111/j.1468-2982.2006.01162.x

8. Emami MJ, Ghahramani MH, Abdinejad F, Namazi H. Q-angle: an invaluable parameter for evaluation of anterior knee pain. Arch Iran Med. 2007;10(7):24-6. PMid:17198449.

9. Mannheimer JS, Rosenthal RM. Acute and chronic postural abnormalities as related to craniofacial pain and temporomandibular disorders. Dent Clin North Am. 1991;35(1):185-208. PMid:1997352.

10. Nicolakis P, Nicolakis M, Piehslinger E, Ebenbichler G, Vachuda M, Kirtley C, et al. Relationship between craniomandibular disorders and poor posture. Cranio. 2000;18(2):106-12. PMid:11202820.

11. Cuccia A, Caradonna C. The relationship between the stomatognathic system and body posture. Clinics. 2009;64(1):61-6. PMid:19142553 PMCid:PMC2671973. http://dx.doi.org/10.1590/S1807-59322009000100011

12. Olivo SA, Bravo J, Magee DJ, Thie NM, Major PW, Flores-Mir C. The association between head and cervical 
posture and temporomandibular disorders: a systematic review. J Orofac Pain. 2006;20(1):9-23. PMid:16483016.

13. Armijo-Olivo S, Rappoport K, Fuentes J, Gadotti IC, Major PW, Warren S, et al. Head and cervical posture in patients with temporomandibular disorders. J Orofac Pain. 2011;25(3):199-209. PMid:21837287.

14. Schürks M, Diener HC. Pathophysiology of migraine and clinical implications. Schmerz. 2008;22(5):523-6, 528-30. PMid:18600349. http://dx.doi.org/10.1007/ s00482-008-0693-1

15. Bevilaqua-Grossi D, Chaves TC, OliveiraAS. Cervical spine signs and symptoms: perpetuating rather than predisposing factors for temporomandibular disorders in women. J Appl Oral Sci. 2007;15(4):259-64. PMid:19089141. http:// dx.doi.org/10.1590/S1678-77572007000400004

16. Sociedade Internacional de Cefaléias. Subcomitê de classificação das cefaleias. Classificação international das cefaléias. 2. ed. Tradução Sociedade Brasileira de Cefaléias. São Paulo: Segmento Farma Editores; 2004.

17. Lipton RB, Stewart WE. Migraine in the US: epidemiology and healthcare use. Neurology. 1993;43(suppl 3):6-10.

18. Manzoni GC, Stovner LJ. Epidemiology of headache. Handb Clin Neurol. 2010;97:3-22. http://dx.doi. org/10.1016/S0072-9752(10)97001-2

19. De Leeuw R. Dor orofacial: guia de avaliação, diagnóstico e tratamento. 4. ed. São Paulo: Quintessence; 2010.

20. Sarlani E, Schwartz AH, Greenspan JD, Grace EG. Chronic paroxysmal hemicrania: a case report and review of the literature. J Orofac Pain. 2003;17(1):74-8. PMid:12756934.

21. Acosta-Ortiz R, Schulte JK, Sparks B, Marsh W. Prediction of different mandibular activities by EMG signal levels. J Oral Rehabil. 2004;31:399-405. PMid:15140163. http:// dx.doi.org/10.1111/j.1365-2842.2004.01251.x

22. Jerjes W, Madland G, Feinmann C, El Maaytah M, Kumar M, Hopper C, et al. Psychoeducation programme for temporomandibular disorders: a pilot study. J Negat Results Biomed. 2007;23:6-4. PMCid:PMC1839113. http://dx.doi.org/10.1186/1477-5751-6-4

23. Gonçalves DA, Speciali JG, Jales LC, Camparis CM, Bigal ME. Temporomandibular symptoms, migraine and chronic daily headaches in the population. Neurology. 2009;73(8):645-6. PMid:19704086. http://dx.doi. org/10.1212/WNL.0b013e3181b389c2

24. Bertoli FM, Antoniuk SA, Bruck I, Xavier GR, Rodrigues DC, Losso EM. Evaluation of the signs and symptoms of temporomandibular disorders in children with headaches. Arq Neuropsiquiatr. 2007;65(2A):251-5. PMid:17607423. http://dx.doi.org/10.1590/S0004-282X2007000200012

25. Ballegaard V, Thede-Schmidt-Hansen P, Svensson $\mathrm{P}$, Jensen R. Are headache and temporomandibular disorders related? A blinded study. Cephalalgia. 2008;28:832-41. PMid:18498400. http://dx.doi. org/10.1111/j.1468-2982.2008.01597.x

26. Bevilaqua Grossi D, Lipton RB, Bigal ME. Temporomandibular disorders and migraine chronification. Curr Pain Headache Rep. 2009;13(4):314-8.
PMid:19586596. http://dx.doi.org/10.1007/ s11916-009-0050-9

27. Bevilaqua-Grossi D, Pegoretti KS, Goncalves MC, Speciali JG, Bordini CA, Bigal ME. Cervical mobility in women with migraine. Headache. 2009;49(5):726-31. PMid:18783446. http://dx.doi.org/10.1111/j.1526-4610.2008.01233.x

28. Gonçalves MC, Florencio LL, Chaves TC, Speciali JG, Bigal ME, Bevilaqua-Grossi D. Do women with migraine have higher prevalence of temporomandibular disorders? Braz J Phys Ther. 2013;17(1):64-8. PMid:23117652. http://dx.doi.org/10.1590/S1413-35552012005000054

29. Dworkin SF, LeResche L. Research Diagnostic Criteria for temporomandibular disorders: review, criteria, examinations and specifications, critique. J Craniomandib Disord. 1992;6(4):300-55. PMid:1298767.

30. Chaves TC, Nagamine HM, De Sousa LM, De Oliveira AS, Grossi DB. Comparison between the reliability levels of manual palpation and pressure pain threshold in children who reported orofacial pain. Man Ther. 2010;15(5):508-12. PMid:20430686. http://dx.doi. org/10.1016/j.math.2010.03.010

31. Raine S, Twomey LT. Head and shoulder posture variations in 160 asymptomatic women and men. Arch Phys Med Rehabil. 1997;78:1215-23. http://dx.doi.org/10.1016/ S0003-9993(97)90335-X

32. Nayler JR. Clinical Photography: A guide for the clinician. J Postgrad Med. 2003;49(3):256-62. PMid:14597792.

33. Claman L, Patton D, Rashid R. Standardized portrait photography for dental patients. Am J Orthod. Dentofac Orthop. 1990;98:197-205. http://dx.doi.org/10.1016/ S0889-5406(05)81596-3

34. Fleiss JL, Levin B, Paik MC. Statistical Methods for Rates and Proportions. Hoboken: John Wiley \& Sons Inc; 2003. http://dx.doi.org/10.1002/0471445428

35. Weir JP. Quantifying test-retest reliability using the intraclass correlation coefficient and the SEM. J Strength Cond Res. 2005;19(1):231-40. PMid:15705040.

36. Portney L, Watkins M. Power and sample size. In: Mehalik C, editor. Foundations of Clinical Research. New Jersey: Prentice Hall Health; 2000. p. 705-30.

37. Cohen J. The concepts of power analysis. In: Cohen J, editor. Statistical power analysis for the behavioral sciences. Hillsdale, New Jersey: Academic Press Inc; 1988. p. 1-17.

38. Lemieux J, Beaton DE, Hogg-Johnson S, Bordeleau LJ, Goodwin PJ. Three methods for minimally important difference: no relationship was found with the net proportion of patients improving. J Clin Epidemiol. 2007;60(5):448-55. PMid:17419955. http://dx.doi. org/10.1016/j.jclinepi.2006.08.006

39. Watson DH, Trott PH. Cervical headache: an investigation of natural head posture and upper cervical flexor muscle performance. Cephalalgia. 1993;13:272-84. http://dx.doi. org/10.1046/j.1468-2982.1993.1304272.x

40. Fernandez-de-las-Peñas C, Pérez-de-Heredia M, MoleroSánchez A, Miangolarra-Page JC. Performance of the craniocervical flexion test, forward head posture, and 
headache clinical parameters in patients with chronic tension-type headache: a pilot study. J Orthop Sports Phys Ther. 2007;37(2):33-9. PMid:17366957. http://dx.doi. org/10.2519/jospt.2007.2401

41. Visscher CM, De Boer W, Lobbezoo F, Habets LLMH, Naeije M. Is there a relationship between head posture and craniomandibular pain? J Oral Rehabil. 2002;29(11):1030-6. PMid:12453255. http://dx.doi. org/10.1046/j.1365-2842.2002.00998.x

42. Iunes DH, Carvalho LCF, Oliveira AS, BevilaquaGrossi D. Craniocervical posture analysis in patients with temporomandibular disorder. Rev Bras Fisioter. 2009;13(1):89-95. http://dx.doi.org/10.1590/ S1413-35552009005000011

43. Lee WY, Okeson JP, Lindroth J. The relationship between forward head posture and temporomandibular disorders. J Orofac Pain. 1995;9(2):161-7. PMid:7488986.
44. Armijo-Olivo S, Warren S, Fuentes J, Magee DJ. Clinical relevance vs. statistical significance: Using neck outcomes in patients with temporomandibular disorders as an example. Man Ther. 2011;16(6):563-72. PMid:21658987. http://dx.doi.org/10.1016/j.math.2011.05.006

\section{Correspondence}

\section{Thais Cristina Chaves}

Universidade de São Paulo

Faculdade de Medicina de Ribeirão Preto

Departamento de Neurociências e Ciências do Comportamento CEP 14049-900, Campus Universitário, Ribeirão Preto, SP, Brasil

e-mail: chavestc@fmrp.usp.br 